\title{
Increased ethanol accumulation from glucose via reduction of ATP level in a recombinant strain of Saccharomyces cerevisiae overexpressing alkaline phosphatase
}

\author{
Marta V Semkiv ${ }^{1}$, Kostyantyn V Dmytruk', Charles A Abbas ${ }^{3}$ and Andriy A Sibirny ${ }^{1,2^{*}}$
}

\begin{abstract}
Background: The production of ethyl alcohol by fermentation represents the largest scale application of Saccharomyces cerevisiae in industrial biotechnology. Increased worldwide demand for fuel bioethanol is anticipated over the next decade and will exceed 200 billion liters from further expansions. Our working hypothesis was that the drop in ATP level in S. cerevisiae cells during alcoholic fermentation should lead to an increase in ethanol production (yield and productivity) with a greater amount of the utilized glucose converted to ethanol. Our approach to achieve this goal is to decrease the intracellular ATP level via increasing the unspecific alkaline phosphatase activity.

Results: Intact and truncated versions of the S. cerevisiae PHO8 gene coding for vacuolar or cytosolic forms of alkaline phosphatase were fused with the alcohol dehydrogenase gene (ADH1) promoter. The constructed expression cassettes used for transformation vectors also contained the dominant selective marker kanMX4 and S. cerevisiae $\delta$-sequence to facilitate multicopy integration to the genome. Laboratory and industrial ethanol producing strains BY4742 and AS400 overexpressing vacuolar form of alkaline phosphatase were characterized by a slightly lowered intracellular ATP level and biomass accumulation and by an increase in ethanol productivity (13\% and $7 \%$ ) when compared to the parental strains. The strains expressing truncated cytosolic form of alkaline phosphatase showed a prolonged lag-phase, reduced biomass accumulation and a strong defect in ethanol production.
\end{abstract}

Conclusion: Overexpression of vacuolar alkaline phosphatase leads to an increased ethanol yield in S. cerevisiae.

Keywords: Baker's yeasts, Ethanol production, PHO8, Alkaline phosphatase, ATP content, Biomass accumulation

\section{Background}

Alcoholic fermentation represents the largest application of the yeast Saccharomyces cerevisiae in the field of industrial biotechnology. In 2011, worldwide fuel ethanol production reached 84.6 billion liters [1]. With increased ethanol use as a biofuel and continued growth in its production for distilled beverages, the worldwide annual production of ethanol will exceed in 2014100 billion liters. Due to economic and environmental reasons, exponential growth in the production of fuel ethanol was observed over the past decade

\footnotetext{
* Correspondence: sibirny@cellbiol.lviv.ua

'Institute of Cell Biology, NAS of Ukraine, Drahomanov Street, 14/16, Lviv 79005, Ukraine

2University of Rzeszow, Zelwerowicza 4, Rzeszow 35-601, Poland

Full list of author information is available at the end of the article
}

[2]. Though lignocellulose is considered to be one of the most promising feedstocks for production of fuel ethanol, its current industrial production relies heavily on fermentation of traditional feedstocks such as sucrose (derived primarily from sugarcane or sugar beets) and glucose obtained from starchy materials (corn, wheat, barley, potatoes etc.). Therefore the construction of the strains of $S$. cerevisiae with elevated ethanol production (yield and productivity) from glucose is of great academic and industrial interest. We decided to reach this goal by manipulation of the ATP content in the cell.

The yeast S. cerevisiae catabolizes glucose via the EmbdenMeyerhof-Parnas (EMP) pathway which yield anaerobically 2 moles ATP per mole of consumed glucose. The efficiency 
of this pathway for anabolic processes is low with a maximal biomass yield of around $7 \%$ and an ethanol yield in the range of $90 \%$ - 93\% from the glucose consumed [3]. Even a slight shift of this ratio in favour of greater ethanol yield from dextrose, can provide an additional several millions litres of ethanol to the worldwide production annually. In contrast to S. cerevisiae, the bacterium, Zymomonas mobilis, ferments glucose through Entner-Doudoroff (ED) pathway. This pathway provides only 1 mole of ATP per mole of glucose, and consequently directs only $3 \%$ of glucose to cell biomass achieving ethanol yield of up to $97 \%$ of the possible theoretical value [4]. This indicates that lowering the ATP yield during alcoholic fermentation increases ethanol yield with reduced substrate conversion to cell mass. Fast fermentation of glucose to ethanol is another important advantage of $Z$. mobilis over $S$. cerevisiae [4,5]. Attempts to substitute $S$. cerevisiae by $Z$. mobilis for the production of industrial ethanol were considered to be a promising approach to increase ethanol yield. However, Z. mobilis has several serious drawbacks which hamper its industrial use and these consist of: (i) a very narrow substrate range (only glucose is efficiently fermented whereas sucrose fermentation is hardly proceeds with low yield), (ii) natural auxotrophy for lysine, methionine and some vitamins, (iii) non-GRAS status, which prevents using cellular biomass as a feed additive, (iv) requirement for a higher $\mathrm{pH}$ for growth [6,7]. Furthermore, the technology of yeast cell utilization for alcoholic fermentation is well developed whereas the use of bacterial cells for ethanol production is far less common. Thus, it looks like construction of the yeast strains which produce less ATP during alcoholic fermentation would be a better approach to increase ethanol yield. These new yeast strains would combine all of the possible advantages of yeast with the high ethanol yield of Z. mobilis. There could be several approaches to achieve this goal, for example: (i) substitution of EMP pathway in yeast by ED pathway from $Z$. mobilis or other bacteria possessing genes of the pathway; (ii) increasing the activity of the enzymes involved in generation of futile cycles; (iii) the introduction of heterologous genes encoding for energy-consuming plasma membrane glucose symporters or (iv) construction of recombinant strains with elevated activity of ATPase of other ATP-degrading enzymes [8].

The first approach to express Escherichia coli ED dehydratase and ED aldolase genes edd and eda in a phosphofructokinase deficient mutant of $S$. cerevisiae has been published [9]. The engineered strains grew and fermented glucose to ethanol, though activities of ED dehydratase and ED aldolase were not reported. It is known that quite often prokaryotic enzymes display low or no activity in S. cerevisiae hosts [10], which is most likely caused by improper folding or instability of the expressed bacterial protein in yeast. In addition, there are difficulties in NADP regeneration in the yeast engineered to possess
ED pathway since NADPH produced in the glucose-6phosphate dehydrogenase reaction, cannot be re-oxidized via alcohol dehydrogenase reaction and yeast does not have NADH/NADPH transhydrogenase activity $[11,12]$.

Alternative approaches to lower ATP level in yeast cell and increase ethanol yield could rely on the activation of some cytosolic ATPases, other ATP hydrolyzing enzymes or via the induction of the some kinds of futile cycles to dissipate cellular pool of ATP, e.g. bacterial or modified yeast fructose-1,6-bisphosphatase [13-15]. There are also published data on decrease of cellular pool of ATP and activation of alcoholic fermentation through overexpression of the soluble part $\left(\mathrm{F}_{1}\right)$ of $\mathrm{H}^{+}$-ATPase or a portion of $\mathrm{F}_{1}$ exhibiting ATPase from different origin in $S$. cerevisiae [16]. Similar results were obtained after overexpression of PHO5 coding for acid phosphatase which is non-specific enzyme hydrolyzing also ATP [15].

In earlier work, we carried out a successful attempt to decrease intracellular ATP level by overexpression of 5' part of the S. cerevisiae SSB1 gene encoding cytosolic ATPase domain and by the heterologous gene apy encoding apyrase from E. coli [17]. In this paper, we describe a new method to lower cellular ATP and increase ethanol yield and productivity during glucose fermentation by overexpression of $S$. cerevisiae intact $\mathrm{PHO} 8$ gene which codes for alkaline phosphatase.

\section{Results and discussion}

Overexpression of the vacuolar forms of alkaline phosphatase in BY4742 laboratory strain

$S$. cerevisiae unspecific alkaline phosphatase (phosphomonoesterase), located in the vacuole, encoded by the gene $\mathrm{PHO}$, catalyses the dephosphorylation of many different compounds including ATP $[18,19]$. Therefore this enzyme may operate as non-specific ATPase. We hypothesized that an increase in alkaline phosphatase activity will reduce intracellular ATP level and thus enhance ethanol production under anaerobic conditions. Several factors should be taken into account to increase specific activity of the target enzyme in yeast. Among these are the copy numbers used for the gene of interest, choice of promoter which controls expression level, stability of the synthetized mRNA, and enzyme feedback inhibition. We have demonstrated that the $A D H 1$ promoter for the gene encoding alcohol dehydrogenase that we used in this work, is very strong and is two-fold activated under the conditions of alcoholic fermentation [O. Kurylenko, K. Dmytruk, A. Sibirny, unpublished observations]. Therefore the $A D H 1$ gene promoter was used for $\mathrm{PHO8}$ gene overexpression. Additional activation of PHO8 overexpression can be achieved by multicopy genomic integration. In order to insert a high copy number of the PHO8 gene into the yeast genome, an integrative plasmid containing $\delta$ sequences was constructed. The 
S. cerevisiae $\delta$ sequences are the long terminal repeats of the retro-transposons Ty1 and Ty2 with an estimated $425 \delta$ sequences dispersed throughout the yeast genome. It was shown that the use of vectors containing $\delta$ sequences can provide tandem multicopy integration in one or several sites of yeast genomic DNA via homologous recombination [20]. The $\delta$ sequences-based plasmid pUC57-delta1_2-ADHpr-PHO8-CYCt-kanMX harboring PHO8 gene under the control of $A D H 1$ promoter was constructed as described in Materials and Methods and subsequently transformed into S. cerevisiae laboratory strain BY4742 (Table 1).

The specific alkaline phosphatase activity of the selected recombinant strains, derivative of BY4742, was assayed. Among 8 tested transformants, six strains were characterized by 30-40 times higher specific phosphatase activity relative to the wild-type strain BY4742 (Figure 1A, strains $1-5$ and 8 ). The data confirm that the constructed expression vector provided multi-copy integration into the genome of S. cerevisiae.

Genomic DNA isolated from the recombinant strains was subjected to dot-blot hybridization to estimate plasmid copy number harbouring target gene, integrated into the genome. Gene PHO8 was used as a probe (Figure 1B). The recombinant strains contained 1-9 additional copies of $\mathrm{PHO} 8$ gene with a good correlation between $\mathrm{PHO} 8$ gene copy number and specific alkaline phosphatase activity was observed.

Southern-hybridization was performed to analyse the vector integration pattern of the tested strains (Figure 2A). Total genomic DNA from wild type and recombinant strains were HindIII digested and hybridized with a labelled $\mathrm{PHO} 8$ gene. The constructed $\delta$ sequences-based vector had tandem multi-copy integration in up to three sites of yeast genomic DNA in the so called "head-to-tail" conformation (Figure 2B), which is in good agreement with previously published results [20].

A selected recombinant strain with substantially enhanced level of specific alkaline phosphatase activity showed small defects in biomass accumulation and intracellular ATP level relative to that of the wild-type strain (Table 2). Ethanol productivity of the wild-type strain BY4742 was $0.79 \mathrm{~g} / \mathrm{L} / \mathrm{h}$

Table 1 Strains and plasmids used in the present investigation

\begin{tabular}{|c|c|c|}
\hline Strains & Genotype & Reference \\
\hline BY4742 & MATa, his $3 \Delta 1$, leu2 $\Delta 0$, lys $2 \Delta 0$, ura $3 \Delta 0$ & {$[21]$} \\
\hline BY4742/Pho8vac & 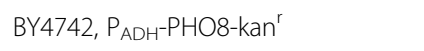 & This study \\
\hline BY4742/Pho8cyt & BY4742, PADH $_{\text {-PHO8_trunc-kan }}{ }^{r}$ & This study \\
\hline AS400 & $\begin{array}{l}\text { Wild type strain commercially used } \\
\text { in bioethanol production at Archer } \\
\text { Daniels Midland Company } \\
\text { (Decatur, IL, USA) }\end{array}$ & This study \\
\hline AS400/Pho8vac & AS400, $\mathrm{P}_{\mathrm{ADH}}-\mathrm{PHO} 8-\mathrm{kan}^{\mathrm{r}}$ & This study \\
\hline
\end{tabular}

or $0.30 \mathrm{~g} / \mathrm{g}$ of biomass $/ \mathrm{h}$, whereas the recombinant strain BY4742/Pho8vac, had a much higher productivity: $0.92 \mathrm{~g} / \mathrm{L} / \mathrm{h}$ or $0.34 \mathrm{~g} / \mathrm{g}$ of biomass $/ \mathrm{h}$ during glucose alcoholic fermentation. The PHO8-overexpressing recombinant strain accumulated $13 \%$ more ethanol as compared to the parental strain BY4742 (Table 2). The data provide proof to our initial hypothesis that the overexpression of alkaline phosphatase can be used to increase ethanol synthesis during glucose alcoholic fermentation.

\section{Overexpression of the vacuolar form of alkaline phosphatase in AS400 industrial strain}

The vacuolar form of alkaline phosphatase was also expressed in the industrial ethanol-producing strain AS400. The plasmid pUC57-delta1_2-ADHpr-PHO8CYCt-kanMX was used for transformation of the strain AS400. Selected transformants AS400/Pho8vac had 2.8-fold increase in the specific activity of alkaline phosphatase as compared to the parental strain AS400 (Table 2). The recombinant strain AS400/Pho8vac with the highest specific activity of alkaline phosphatase and the parental AS400 strain were tested for the efficiency of alcoholic fermentation in a mineral YNB medium supplemented with $20 \%$ glucose. Biomass and ethanol accumulation was measured in transformant AS400/Pho8vac and the parental strain AS400 (Figure 3). Based on the results, it was determined that the transformant AS400/Pho8vac accumulated 6\% more ethanol relative to parental strain during fermentation producing $5.37 \mathrm{~g} / \mathrm{L} / \mathrm{h}$ of ethanol versus $5.07 \mathrm{~g} / \mathrm{L} / \mathrm{h}$ for AS400 strain (Figure 3). Due to slight difference in the biomass accumulation and complete glucose consumption during fermentation, differences in ethanol production between parental and recombinant strains may be caused by the decrease of byproducts accumulation like glycerol, acetate or reduced amount of reserve carbohydrates. The recombinant strain AS400/Pho8vac was also tested for the efficiency of alcoholic fermentation in a CSL medium supplemented with hydrolysed corn meal. This strain was shown to have substantially increased productivity of ethanol synthesis $(3.75 \mathrm{~g} / \mathrm{L} / \mathrm{h})$ as compared to that of the parental strain $(3.3 \mathrm{~g} / \mathrm{L} / \mathrm{h})$ (Table 2). Ethanol yield per gram of consumed glucose was found to be increased $13.6 \%$ (Table 2). Measurement of the productivity of ethanol synthesis per biomass was not carried out in CSL medium as it contains many small insoluble particles which hamper cell biomass measurement using direct dry weight or by optical density analyses. The recombinant strains tested were all also characterized by substantially lower intracellular ATP level relative to the parental strain AS400 (Table 2). We do not exclude the possibility that the drop in intracellular ATP level may have a negative impact on biomass accumulation during aerobic large-scale cultivation, but we assume that this effect will be insignificant, since biomass accumulation of recombinant strain 
A

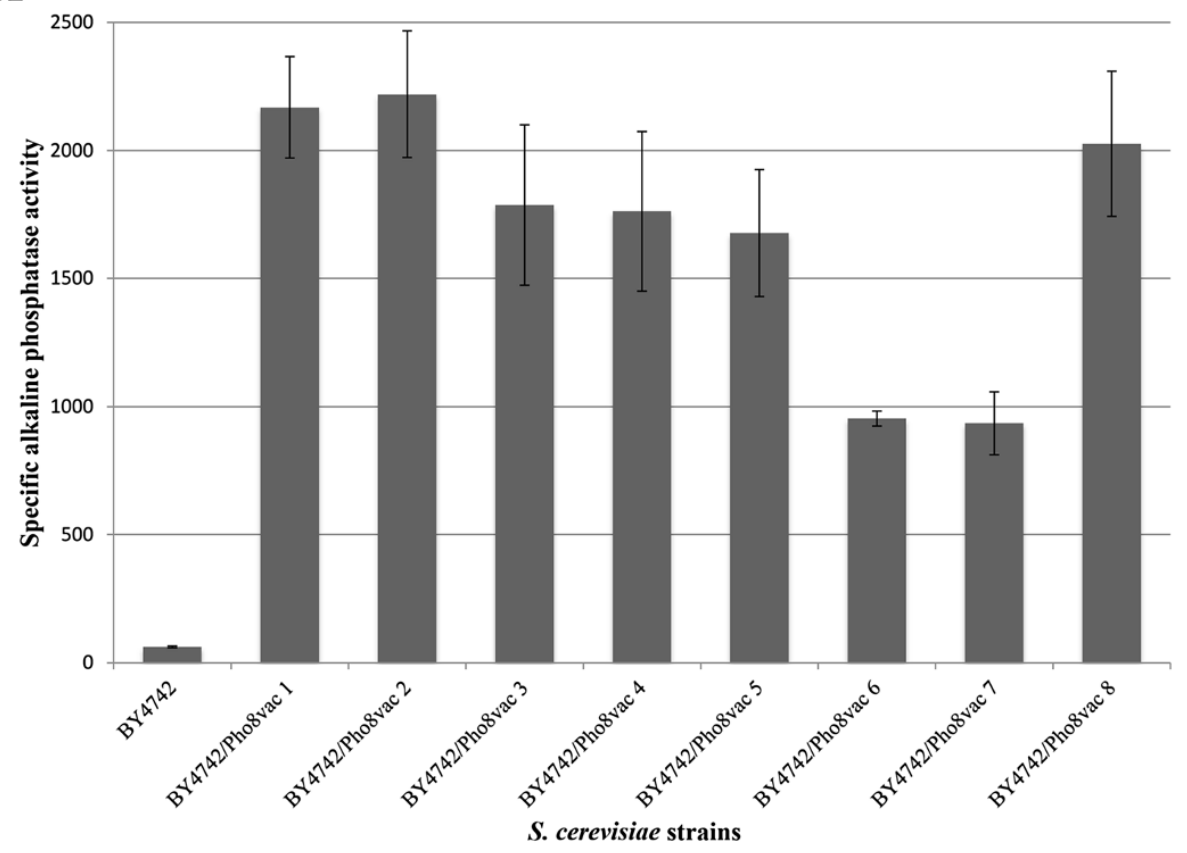

B

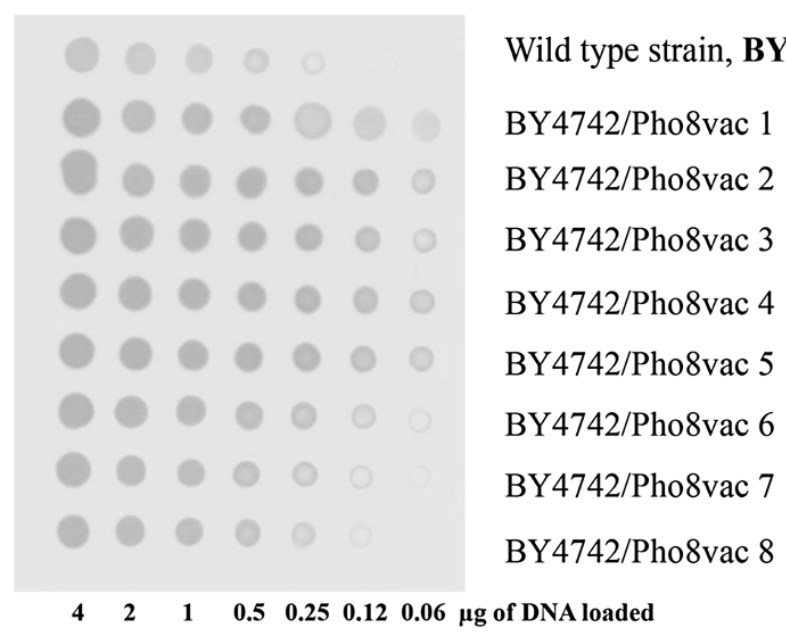

Figure 1 Specific alkaline phosphatase activity in nmoles of product/mg of prot.*min (A) and estimation of integrated expression cassette copy number by dot-blot hybridization (B) in the S. cerevisiae transformants and control strain. BY4742 - recipient strain; BY4742/Pho8vac - recombinant strains bearing plasmid pUC57-delta1_2-ADHpr-PHO8-CYCt-kanMX. Alkaline phosphatase activity is shown in nmoles of product/mg of prot.*min. For dot-blot hybridization genomic DNA was isolated from WT and recombinant strains, diluted and loaded onto nitrocellulose film. Amounts of loaded DNA is shown under the photo. PHO8 gene was used as a probe.

AS400/Pho8vac didn't differ substantially from the parental strain AS400 in the experiments we carried out (Figure 3A).

\section{Overexpression of the cytosolic form of alkaline phosphatase in BY4742}

The results demonstrate that the overexpression of vacuolar alkaline phosphatase leads to an increase in ethanol production during alcoholic fermentation of glucose in laboratory and industrial strains of $S$. cerevisiae. This is due to the accelerated hydrolysis of substrate via increased activity from overexpression of vacuolar alkaline phosphatase. The target substrates are polyphosphates which are known to be the natural substrates of alkaline phosphatase [21]. As the synthesis of polyphosphates requires ATP, an increase in alkaline phosphatase activity may lead 


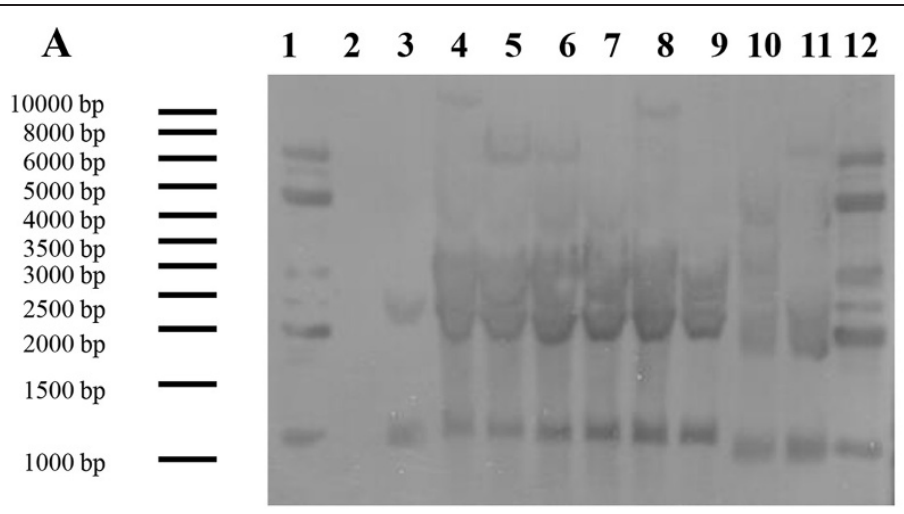

B

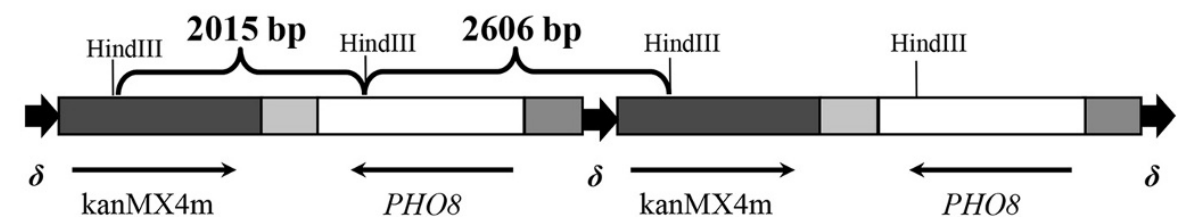

Figure 2 Analysis of expression cassette integration pattern. (A) Southern hybridization. PHO8 gene was used as a probe. Hindlll was used for genomic DNA restriction. 1, 12 - plasmid pUC57-delta1_2-ADHpr-PHO8-CYCt-kanMX; 2 - ladder; 3 - wild type strain, BY4742; 4-11 - BY4742/ Pho8vac - recombinant strains containing vector pUC57-delta1_2-ADHpr-PHO8-CYCt-kanMX; B) "head-to-tail" conformation of vector integration.

to a futile cycle of ATP consumption which enhances need for ATP to replenish again the vacuolar polyphosphate pool [22]. We decided to check the effects of overexpression of the truncated forms of alkaline phosphatase which lack putative vacuolar targeting signal. A recombinant strain expressing truncated version of $\mathrm{PHO} 8$ gene was constructed. Alkaline phosphatase is synthesized as an inactive precursor containing a C-terminal propeptide that is afterwards cleaved from the protein in yeast vacuoles in a Pep4-dependent manner [19]. During vacuolar delivery, which shares the early stages with the secretory pathway, the precursor form of this enzyme is glycosylated in the endoplasmic reticulum. It has also been shown that the active form of alkaline phosphatase binds with the metal co-factor zinc in the vacuole rather than in earlier compartments of the secretory pathway [23]. A truncated form of this enzyme was constructed which lacks 60 initial amino acids that are responsible for transmembrane protein delivery; and additionally 22 terminal amino acids, that represent the C-terminal propeptide that is normally cleaved from the protein in the vacuole $[19,23]$. The DNA fragment containing the expression cassette of the truncated $\mathrm{PHO} 8$ gene in part with selective marker flanked by $\delta$ sequences were used for transformation of BY4742 strain of $S$. cerevisiae. The specific alkaline phosphatase activity of the selected recombinant strain BY4742/Pho8cyt was assayed and compared with that of the strain BY4742/Pho8vac. The intracellular alkaline phosphatase

Table 2 Growth rate, ATP level, AP activity, ethanol productivity and yield of S. cerevisiae transformants and control strains

\begin{tabular}{|c|c|c|c|c|c|c|}
\hline \multirow[t]{2}{*}{ Strain } & \multirow{2}{*}{$\begin{array}{l}\text { Specific growth } \\
\text { rate, } g / L / h^{*}\end{array}$} & \multirow{2}{*}{$\begin{array}{l}\text { ATP, } \mu \text { moles } \\
\text { of ATP } / \mathrm{mg} \mathrm{dry}^{*} \\
\text { cell weight }^{* *}\end{array}$} & \multirow{2}{*}{$\begin{array}{l}\text { Alcaline phosphatase } \\
\text { activity, nmoles of } \\
\text { product } / \mathrm{mg}_{\text {of }} \\
\text { prot.* min. }\end{array}$} & \multicolumn{2}{|c|}{ Ethanol productivity } & \multirow{2}{*}{$\begin{array}{l}\text { Ethanol yield } g / 9 \\
\text { of consumed } \\
\text { glucose }\end{array}$} \\
\hline & & & & g/L/h & $\begin{array}{c}\mathrm{g} / \mathrm{L} / \mathrm{g} \text { of } \\
\text { biomass } / \mathrm{h}\end{array}$ & \\
\hline BY4742 & $0.031 \pm 0.002$ & $7.95 \pm 0.10$ & $85.2 \pm 3.3$ & $0.79 \pm 0.014$ & $0.30 \pm 0.006$ & $0.379 \pm 0.007$ \\
\hline BY4742/Pho8vac & $0.032 \pm 0.001$ & $7.83 \pm 0.06$ & $1948.3 \pm 175.3$ & $0.92 \pm 0.019$ & $0.34 \pm 0.007$ & $0.442 \pm 0.009$ \\
\hline BY4742/Pho8cyt & $0.025 \pm 0.001$ & $7.56 \pm 0.08$ & $1832.4 \pm 137.4$ & $0.42 \pm 0.004$ & $0.18 \pm 0.002$ & $0.202 \pm 0.002$ \\
\hline AS400 & & $8.93 \pm 0.15$ & $45.3 \pm 2.5$ & $3.30 \pm 0.083$ & & $0.396 \pm 0.010$ \\
\hline AS400/Pho8vac & & $8.11 \pm 0.18$ & $125.3 \pm 4.4$ & $3.75 \pm 0.075$ & & $0.450 \pm 0.010$ \\
\hline
\end{tabular}

"Results of three independent tests.

***esults of two independent tests. 

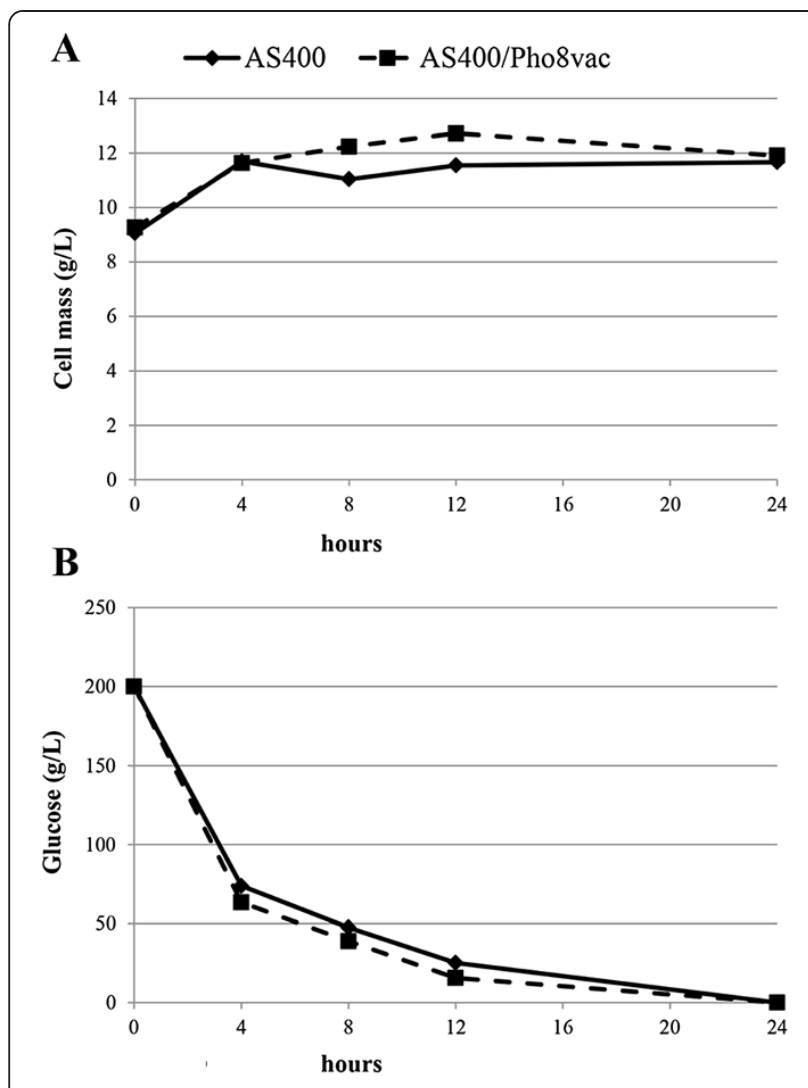

C

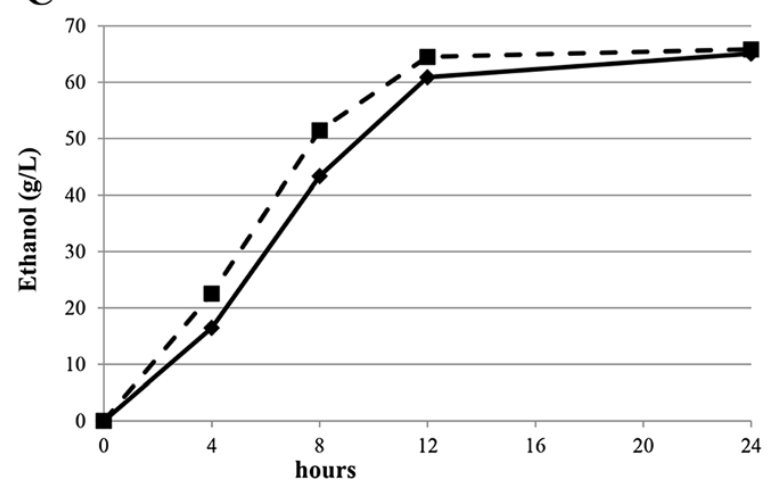

Figure 3 Growth, glucose consumption and ethanol production during alcoholic fermentation of recombinant strains overexpressing vacuolar form of alkaline phosphatase. Strains were cultured under semianaerobic conditions in YNB medium with $200 \mathrm{~g} / \mathrm{L}$ D-glucose. Cultures were incubated at $30^{\circ} \mathrm{C}$, shaking at 120 rpm using. AS400 - WT, recipient strain. AS400/Pho8vac - strain containing vector pUC57-delta1_2-ADHpr-PHO8-CYCt-kanMX. A - biomass accumulation ( $\mathrm{g}$ of biomass $/ \mathrm{L}$ of medium); $\mathbf{B}$ - glucose consumption ( $\mathrm{g}$ of glucose/L of medium); $\mathbf{C}$ - ethanol production ( $\mathrm{g}$ of ethanol/L of medium).

activity in the strain BY4742/Pho8cyt was at the same level as in the strain BY4742/Pho8vac overexpressing the intact form of PHO8 (Table 2).

Growth kinetics of the constructed recombinant strains was measured. An equal amount of cellular biomass
$(0.015 \mathrm{~g} / \mathrm{L})$ of wild-type strain and recombinant strains were inoculated into the mineral media containing $10 \%$ glucose as a carbon source. The strain with truncated PHO8 form was characterized by a longer lag-phase during the first day of cultivation (not shown), with lowered biomass accumulation and a reduced growth rate (Table 2). This recombinant strain (BY4742/Pho8cyt) had the highest specific activity of cytosolic form of alkaline phosphatase showed a decrease in the intracellular ATP level (Table 2).

Recombinant strain BY4742/Pho8cyt has produced significantly less ethanol during glucose alcoholic fermentation relative to recombinant strains with overexpressed native alkaline phosphatase and the wild-type strain BY4742, i.e. only about $0.42 \mathrm{~g} / \mathrm{L} / \mathrm{h}$ or $0.18 \mathrm{~g} / \mathrm{g}$ of biomass/h (Table 2). We hypothesize that the cytosolic form of alkaline phosphatase decreases not only the level of ATP but also that of other sugar phosphate intermediates as well as regulators like fructose-2,6-bisphosphate, leading to detrimental effect on ethanol production. However, confirmation of this hypothesis requires additional experiments which are in progress.

\section{Conclusion}

This study established a new successful approach to increasing ethanol production from glucose in S. cerevisiae by homologous overexpression of $\mathrm{PHO} 8$ gene due to multiple genomic insertion events. The overexpression of intact $\mathrm{PHO}$ gene encoding vacuolar form of alkaline phosphatase led to decline in intracellular ATP level and biomass accumulation and up to $13 \%$ increase in ethanol productivity. By comparison, the overexpression of truncated form of $\mathrm{PHO}$ gene encoding presumably cytosolic form of alkaline phosphatase caused a significant drop both in biomass accumulation and ethanol production. In conclusion, the overexpression of the intact vacuolar form of alkaline phosphatase results in overproduction of ethanol in laboratory and industrial strains of S. cerevisiae.

\section{Methods}

Strains, media, growth and fermentation conditions

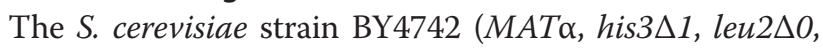
lys $2 \Delta 0$, ura $\Delta 0$; [24] and an industrial strain AS400 (obtained from Archer Daniels Midland Company, Decatur, IL, USA) (Table 1) were used for the expression of the intact or truncated version of PHO8 ORF coding for alkaline phosphatase. For selection of yeast transformants on YPD, $200 \mathrm{mg} / \mathrm{L}$ of geneticin was added. When required, histidine $(20 \mathrm{mg} / \mathrm{L})$, leucine $(60 \mathrm{mg} / \mathrm{L})$, lysine $(20 \mathrm{mg} / \mathrm{L})$, or uracil $(20 \mathrm{mg} / \mathrm{L})$ were added.

S. cerevisiae strains were incubated at $30^{\circ} \mathrm{C}$. Yeast strains were maintained in rich YPD ( $1 \%$ yeast extract, $1 \%$ peptone and $2 \%$ glucose) or mineral YNB $(0.67 \%$, yeast 
nitrogen base without amino acids, DIFCO, 0.5\% ammonium sulfate, $2 \%$ glucose) media. For ethanol fermentation, all strains were tested with a YNB medium that was supplemented with $10 \%$ glucose or by using a medium containing corn steep liqour (CSL) supplemented with hydrolyzed corn meal as the primary carborn source.

The corn steep liquor (CSL) medium was prepared by combining two solutions that were prepared as follows. Solution 1 was prepared by adding $200 \mathrm{~g}$ of corn meal (Melvit, Poland) was mixed with $800 \mathrm{ml}$ of water and $\mathrm{pH}$ adjusted to 6.0 using $\mathrm{NaOH}$. The enzyme alphaamylase (Liquizyme SC) was added at a rate of 0.1 units of per gram of meal and the slurry was liquefied by heating the mixture to $80^{\circ} \mathrm{C}$ for 30 minutes. To prepare Solution 2, $63 \mathrm{ml}$ of CSL Concentrate (containing 50\% dry solids) was mixed with $137 \mathrm{ml}$ of deionized water. The two solutions were autoclaved, cooled, combined and mixed. The enzyme glucoamylase (Liquizyme SC) was added at a rate of 0.2 units of glucoamylase per gram of meal to sterile flasks and the flasks were incubated at $28^{\circ} \mathrm{C}$. Glucose concentration was measured in control flasks without yeast inoculation at 180-200 g/L in the CSL medium prepared.

Cells of BY4742 strain and its PHO8-expressing derivatives were grown in $100 \mathrm{ml}$ of YPD medium in Erlenmeyer flasks (bottle size - $300 \mathrm{ml}$ ) overnight and then used to inoculate a $20 \mathrm{ml}$ of YNB medium with $10 \%$ glucose in $50 \mathrm{ml}$ Erlenmeyer flasks. An initial biomass concentration of $1.2 \mathrm{~g}$ (dry weight)/L was used for fermentation. Fermentation was carried out at a temperature of $30^{\circ} \mathrm{C}$ with limited aeration using a gyratory shaker at a setting of 120 revolutions/min.

For the S. cerevisiae AS400 strain and its PHO8-expressing derivatives, both YNB medium with $20 \%$ glucose and CSL medium supplemented with hydrolyzed meal were used in fermentation tests. An initial biomass concentration of $10 \mathrm{~g}$ (dry weight)/L was used for fermentation as this is the cell density normally used in industrial ethanol fermentation [25]. Strains were incubated under semi-anaerobic condition at $34^{\circ} \mathrm{C}$ for 2 days and samples were taken every 24 hours.

The E. coli DH5 $\alpha$ strain (Ф80dlacZ $\Delta \mathrm{M} 15$, recA1, endA1, gyrA96, thi-1, hsdR17( $\left.\mathrm{r}_{\mathrm{K}}^{-}, \mathrm{m}_{\mathrm{K}}^{+}\right)$, supE44, relA1, deoR, $\triangle($ lacZYA-argF)U169) was used as a host for propagation of plasmids. Strain $\mathrm{DH} 5 \alpha$ was grown at $37^{\circ}$ $C$ in LB medium as described previously [26]. Transformed E. coli cells were maintained on a medium containing $100 \mathrm{mg} / \mathrm{L}$ of ampicillin. The chromogenic substrates X-gal and IPTG (Fermentas, Vilnius, Lithuania) were used according to the manufacturer specifications.

\section{DNA manipulations}

Genomic DNA from $S$. cerevisiae strains was isolated using the Wizard ${ }^{\oplus}$ Genomic DNA Purification Kit (Promega,
Madison, WI, USA). Plasmid DNA from E. coli was isolated using the Wizard ${ }^{\oplus}$ Plus SV Minipreps DNA Purification System (Promega). Taq and High Fidelity polymerase mix, T4 DNA ligase, T4 DNA polymerase and restriction enzymes were used according to recommendation of supplier (Fermentas). S. cerevisiae transformation was performed by standard protocol [26].

\section{Plasmid construction}

Expression cassette preparation. 154 bp 5'- and $180 \mathrm{bp}$ 3'-parts of S. cerevisiae YJRWdelta12 sequence were amplified from genomic DNA of $S$. cerevisiae strain BY4742 using pairs of primers SM16/SM17 and SM18/ SM19 (Table 3). Both delta sequences were fused via overlap PCR using primers SM16 and SM19, digested with EcoRI and HindIII and cloned into EcoRI/HindIII-linearized plasmid pUC57. The constructed plasmid was designated pUC57-delta1_2. Fragments of DNA having 807 bp and 269 bp bearing promoter of $A D H 1$ gene encoding alcohol dehydrogenase and terminator of $C Y C 1$ gene encoding cytochrome $\mathrm{C}$, were amplified from genomic DNA of BY4742 by pairs of primers Ko419/Ko420 and Ko453/ Ko454, respectively. The $A D H 1$ promoter and $C Y C 1$ terminator were fused via overlap PCR using primers Ko419 and Ko454 and SalI/XmaI cloned into the corresponding sites of the plasmid pUC57-delta1_2 resulting in the plasmid pUC57-delta1_2-ADHpr-CYCt. A 1470 bp DNA fragment corresponding to the selective marker kanMX providing resistance to geneticin was cut out from the plasmid pRS303K [27] with restriction endonucleases SacI and SmaI, blunt-ended and cloned into XbaI-digested and blunted plasmid pUC57-delta1_2-ADHpr-CYCt yielding the plasmid pUC57-delta1_2-ADHpr-CYCt-kanMX (Figure 4A).

Plasmid for expression of native PHO8. A 1701 bp DNA fragment bearing the ORF of PHO8 gene coding for unspecific alkaline phosphatase was amplified from genomic DNA of the BY4742 strain using primers Ko508 and Ko509. This fragment was digested with BamHI and NotI and subcloned into BamHI/NotI digested plasmid pUC57-delta1_2-ADHpr-CYCt-kanMX. This plasmid was designated pUC57-delta1_2-ADHpr-PHO8-CYCt-kanMX (Figure 4B).

Plasmid for expression of truncated version of PHO8 gene. The cytosolic form of Pho8 lacking 60 initial amino acids which are responsible for transmembrane protein delivery; and 22 terminal amino acids composing the C-terminal propeptide that is normally cleaved from the protein in vacuole, was isolated. A 1452 bp DNA fragment corresponding to this truncated form, was amplified from genomic DNA of BY4742 strain using primers SM28 and SM29, digested with endonucleases BamHI and NotI and cloned into BamHI/NotI digested plasmid pUC57-delta1_2-ADHpr-PHO8-CYCt-kanMX. 
Table 3 DNA oligonucleotides used in this study

\begin{tabular}{|c|c|c|}
\hline Primer names & Sequence $\left(5^{\prime}-3^{\prime}\right)$ restriction sites are italic & Restriction sites \\
\hline SM16 & CCGGAATTC ${ }^{\mathrm{a}}$ GACGGGCAGTC ${ }^{\mathrm{b}} \mathrm{TGTTGGAATAGAAATCAACTATC}$ & EcoRla ${ }^{a}$,Ahdl ${ }^{b}$ \\
\hline SM17 & CATCATTTTATATGTTTATATTCATCTAGA ${ }^{a} C C C G G G^{b}$ GTCGAC ${ }^{c}$ TTGATCCTATTACATTATCAATCC & $\mathrm{Xbal}^{\mathrm{a}}, \mathrm{Xmal}^{\mathrm{b}}$, Sall ${ }^{\mathrm{c}}$ \\
\hline SM18 & GGATTGATAATGTAATAGGATCAAGTCGAC CCCGGG ${ }^{\mathrm{b}}{ }^{\mathrm{a} C T A G A^{\mathrm{C}} \mathrm{TGAATATAAACATATAAAATGATG}}$ & Salla ${ }^{a} \mathrm{Xmal}^{b}, \mathrm{Xbal}^{\mathrm{c}}$ \\
\hline SM19 & CCCAAGCTT'aACGGGCAGTC ${ }^{\mathrm{a}}$ TGAGAAATATGTGAATGTTGAG & HindlII ${ }^{a}$ Ahdl ${ }^{b}$ \\
\hline SM28 & CGCGGATCC ${ }^{\mathrm{a}}$ TTGTCTGCATCACACAAGAAGAAGAATGTC & $\mathrm{BamH}^{\mathrm{a}}$ \\
\hline SM29 & 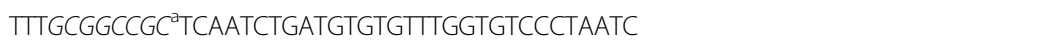 & $\mathrm{Notl}^{\mathrm{a}}$ \\
\hline Ko419 & CGCGTCGAC TTAATTAAAGTCCAATGCTAG & Sall \\
\hline Ko420 & GATATCGACAAAGGAAAAGGGGCGGCCGC ${ }^{\mathrm{a}} G$ GATCC ${ }^{\mathrm{b}}{ } T C G A G^{\mathrm{c}} \mathrm{TGTATATGAGATAGTTGATTG}^{-}$ & Notl $^{a}$, BamHll $^{b}$, Xhol $^{c}$ \\
\hline Ko453 & CAATCAACTATCTCATATACACTCGAG GGATCC ${ }^{\mathrm{b}} G C G G C C$ GC CCCCTITCCTTGTCGATATC & $\mathrm{Xhol}^{a}, \mathrm{BamHI}^{\mathrm{b}}, \mathrm{Notl}^{\mathrm{c}}$ \\
\hline Ko454 & CCCCCCGGG GCAAATTAAAGCCTTCGAGC & $X m a l^{a}$ \\
\hline Ko508 & CGCGGATCC ATGATGACTCACACATTACCAAGC & $\mathrm{BamH}^{\mathrm{a}}$ \\
\hline Ko509 & TITGCGGCCGC ${ }^{\mathrm{a}}$ TCAGTTGGTCAACTCATGGTAGTATTC & $\mathrm{Notl}^{\mathrm{a}}$ \\
\hline
\end{tabular}

$\overline{a, b, c}$ Restriction sites with corresponding restriction enzyme.

The constructed plasmid was designated as pUC57delta1_2-ADHpr-PHO8_trunc-CYCt-kanMX (Figure 4C).

\section{Selection of S. cerevisiae transformants}

The vectors containing native or modified versions of the PHO8 gene were digested with the AhdI. AhdI-fragments containing expression cassettes and selective marker flanked by $\delta$-sequences, were eluted from an agarose gel and used for transformation of $S$. cerevisiae strains BY4742 and AS400. The transformants were selected on a solid YPD medium supplemented with $200 \mathrm{mg} / \mathrm{L}$ of geneticin. The selected transformants were stabilized by alternating cultivation in non-selective and selective media and examined by diagnostic PCR using a forward primer Ko419 specific to the $A D H 1$ promoter and a reverse one Ko509 specific to $\mathrm{PHO} 8$ gene.

\section{Biochemical methods and analyses}

The specific activity of alkaline phosphatase was assayed in cell free extracts using the chromogenic substrate p-nitrophenyl phosphate as described elsewhere [18]. The assay was repeated three times and the measurement reported is an average of these determinations. The numbers reported use one unit of alkaline phosphatase activity

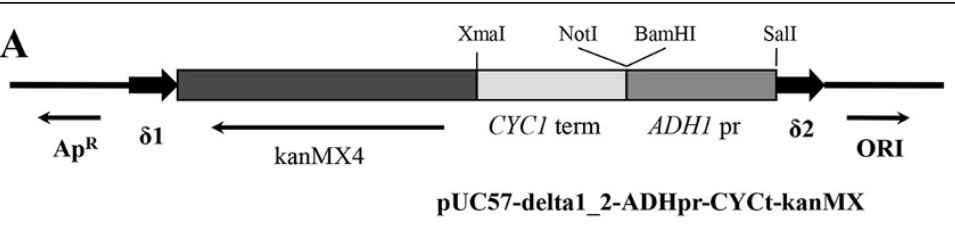

B

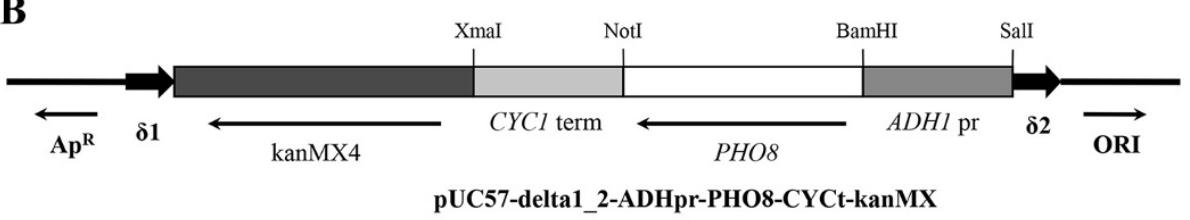

C

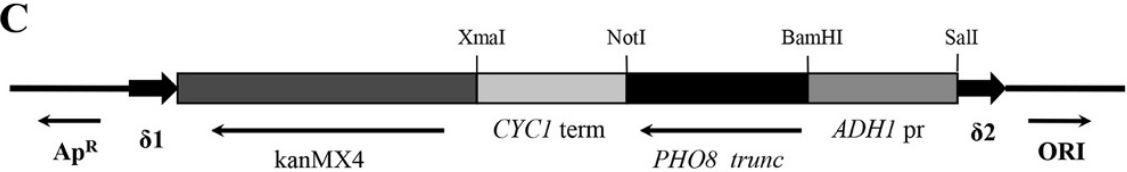

pUC57-delta1_2-ADHpr-PHO8_trunc-CYCt-kanMX

Figure 4 Linear schemes of plasmids used in this study: pUC57-delta1_2-ADHpr-CYCt-kanMX (A), pUC57-delta1_2-ADHpr-PHO8-CYCt-kanMX (B), pUC57-delta1_2-ADHpr-PHO8_trunc-CYCt-kanMX (C). $\delta$ elements are shown as thick black arrows. ADH1 promoter, CYC1 terminator and kanMX4 gene are shown as chessboard-alike, doted and diagonal-hatched boxes, respectively. Unmodified PHO8 gene ORF is shown as white box and truncated PHO8 gene ORF is shown as black doted box. Origin of replication ORI and ampicillin resistance gene (bla) are shown as thin arrows. 
as the amount of enzyme that liberates $1 \mu \mathrm{mol}$ of $\mathrm{p}$ nitrophenol per min under the assay conditions.

Measurements of ATP were carried out following extraction of this metabolite from the $S$. cerevisiae cells was using boiling ethanol and subsequent evaporation [28]. In order to optimize ATP assay condition for ethanol extraction, a wide range of yeast biomass from 2 to $15 \mathrm{mg}$ was tested. Reproducible results were obtained during ATP extraction with 8-10 $\mathrm{mg}$ of $S$. cerevisiae cells using $1 \mathrm{ml}$ of boiling ethanol. Extracted ATP was measured by coupled enzymatic reactions with hexokinase and glucose-6-phosphate dehydrogenase [29].

The concentration of ethanol in fermentation media was determined using alcohol oxidase/peroxidase-based enzymatic kit "Alcotest" [30,31]. The biomass was determined using turbidity with a Helios Gamma spectrophotometer (OD, $600 \mathrm{~nm}$; cuvette, $10 \mathrm{~mm}$ ) with gravimetric calibration. Glucose concentration was determined using the "Diagluc" assay kit (UBT, Lviv) [30]. All samples were assayed at least twice to ensure results are reproducible.

\section{Competing interests}

The authors declare that they have no competing interests.

\section{Authors' contributions}

MVS carried out gene engineering manipulations, enzyme activity assays and alcoholic fermentations. KVD participated in design of cloning and strain construction, analyzed the date and co-drafted the manuscript. CAA participated in plasmids sequencing, commented and approved the manuscript. AAS provided guidance and suggestions for experimental design and edited the manuscript. All authors have read and approved the manuscript.

\section{Acknowledgement}

This work was supported in part by Archer Daniels Midland Company (Decatur, IL); Polish grant of National Scientific Center (NCN) DEC-2012/05/B/ NZ1/01657 awarded to AAS and FEMS Fellowship grant \# UA-SMU2012-2 awarded to MVS.

\section{Author details}

'Institute of Cell Biology, NAS of Ukraine, Drahomanov Street, 14/16, Lviv 79005, Ukraine. ${ }^{2}$ University of Rzeszow, Zelwerowicza 4, Rzeszow 35-601, Poland. ${ }^{3}$ Archer Daniels Midland Co Research Center, 1001 N Brush College Rd, Decatur, IL 62521, USA.

Received: 6 March 2014 Accepted: 7 May 2014

Published: 15 May 2014

\section{References}

1. Renewable Fuels Association: Acelerating Industry Innovation - 2012 Ethanol Industry Outlook. Washington, DC: Renewable Fuels Association; 2012:3, 8, 10, 22-23.

2. Schubert C: Can biofuels finally take center stage? Nat Biotechnol 2006, 24:777-784.

3. Ingledew WM: Alcohol production by Saccharomyces cerevisiae: a yeast primer, in the alcohol textbook. 3rd edition. UK: Nottingham University Press; 1999.

4. Sprenger GA: Carbohydrate metabolism in Zymomonas mobilis: a catabolic highway with some scenic routes. FEMS Microbiol Lett 1996, 145:301-307.

5. Panesar PS, Marwaha SS, Kennedy JF: Zymomonas mobilis: an alternative ethanol producer. J Chem Technol Biotechnol 2006, 81:623-635.

6. Jeffries TW: Ethanol fermentation on the move. Nature 2005, 23:40-41

7. Bai FW, Anderson WA, Moo-Young M: Ethanol fermentation technologies from sugar and starch feedstocks. Biotechnol Adv 2008, 26:89-105.

8. De Kok S, Kozak B, Pronk J, Van Maris A: Energy coupling in Saccharomyces cerevisiae: selected opportunities for metabolic engineering. FEMS Yeast Res 2012, 12:387-97.
9. Lancashire WE, Dickinson JR, Malloch RA: DNA encoding enzymes of the glycolytic pathway for use in alcohol producing yeast. US Patent 1998, 5786186:A1.

10. Hahn-Hagerdal B, Karhumaa K, Jeppsson M, Gorwa-Grauslund MF: Metabolic Engineering for Pentose Utilization in Saccharomyces cerevisiae. Adv Biochem Engin Biotechnol 2007, 108:147-177.

11. Leskovac V, Trivic S, Peric D: The three zinc-containing alcohol dehydrogenases from baker's yeast, Saccharomyces cerevisiae. FEMS Yeast Res 2002, 2:481-494.

12. Jeffries TW, Jin Y-S: Metabolic engineering for improved fermentation of pentoses by yeasts. Appl Microbiol Biotechnol 2004, 63:495-509.

13. Navas MA, Cerdan S, Gancedo JM: Futile cycles in Saccharomyces cerevisiae strains expressing the gluconeogenic enzymes during growth on glucose. Prot Natl Acad Sci USA 1993, 90:1290-1294.

14. Navas MA, Gancedo JM: The regulatory characteristics of yeast fructose-1,6-bisphosphatase confer only a small selective advantage. J Bacteriol 1996, 178:1809-1812.

15. Rogers DT, Szostak JW: Strains of yeast with increased rates of glycolysis. US Patent 1993, 5268285:A1.

16. Jensen $\mathrm{P}$, Snoep J, Westerhoff $\mathrm{H}$ : Method of improving the production of biomass or a desired product from a cell. US Patent 2006, 20060094078:A1.

17. Dmytruk KV, Semkiv MV, Sibirny AA: Ethanol yield and reduction of biomass accumulation in the recombinant strain of Saccharomyces cerevisiae overexpressing ATPase. US Patent Application 2012, 0088290:A1

18. Kaneko Y, Akio Toh E, Oshima Y: Identification of the Genetic Locus for the Structural Gene and a New Regulatory Gene for the Synthesis of Repressible Alkaline Phosphatase in Saccharomyces cerevisiae. Mol Cell Biol 1982, 2:127-137.

19. Klionsky DJ, Emr SD: Membrane protein sorting: biosynthesis, transport and processing of yeast vacuolar alkaline phosphatase. EMBO J 1989, 8:2241-2250.

20. Lee FW, Da Silva NA: Improved efficiency and stability of multiple cloned gene insertions at the $\delta$ sequences of Saccharomyces cerevisiae. Appl Microbiol Biotechnol 1997, 48:339-345.

21. Fernandez M, Gascon S, Schwencke J: Some enzymatic properties of vacuolar alkaline phosphatase from yeast. Curr Microbiol 1981, 6:121-126.

22. Klionsky DJ, Herman PK, Emr SD: The Fungal Vacuole: Composition Function, and Biogenesis. Microbiol Rev 1990, 54:266-292.

23. Qiao W, Ellis C, Steffen J, Wu J-Y, Eide D: Zinc status and vacuolar zinc transporters control alkaline phosphatase accumulation and activity in Saccharomyces cerevisiae. Mol Cell Biol 1985, 5:248-252.

24. Giaever G, Chu AM, Ni L, Connelly C, Riles L, Veronneau S, Dow S, Lucau-Danila A, Anderson K, André B, Arkin AP, Astromoff A, El-Bakkoury M, Bangham R, Benito R, Brachat S, Campanaro S, Curtiss M, Davis K, Deutschbauer A, Entian KD, Flaherty P, Foury F, Garfinkel DJ, Gerstein M, Gotte D, Güldener U, Hegemann JH, Hempel S, Herman Z, et al: Functional profiling of the Saccharomyces cerevisiae genome. Nature 2002, 418:387-391.

25. Lin Y, Tanaka S: Ethanol fermentation from biomass resources: current state and prospects. Appl Microbiol Biotechnol 2006, 69:627-642.

26. Sambrook J, Russell DW: Molecular cloning: a laboratory manual. 3rd edition. New York: Cold Spring Harbor Laboratory Press; 2001.

27. Taxis C, Knop M: System of centromeric, episomal, and integrative vectors based on drug resistance markers for Saccharomyces cerevisiae. Biotechniques 2006, 40:73-78.

28. Entian K-D, Droll L, Mecke D: Studies on rapid reversible and non-reversible inactivation of fructose-1,6-bisphosphate and malate dehydrogenase in Wild-type and glycolytic block mutants of Saccharomyces cerevisiae. Arch Microbiol 1983, 134:187-192.

29. Ano Y, Hattori T, Kato N, Sakai Y: Intracellular ATP correlates with mode of pexophagy in Pichia pastoris. Biosci Biotechnol Biochem 2005, 69:1527-1533.

30. Gonchar MV: Sensitive method for quantitative determination of hydrogen peroxide and oxidase substrates in biological samples. Ukr Biokhim Zh 1998, 70:157-163.

31. Gonchar MV, Maidan MM, Pavlishko HM, Sibirny AA: A new oxidase-peroxidase kit for ethanol assays in alcoholic beverages. Food Technol Biotechnol 2001, 39:37-42.

\section{doi:10.1186/1472-6750-14-42}

Cite this article as: Semkiv et al:: Increased ethanol accumulation from glucose via reduction of ATP level in a recombinant strain of Saccharomyces cerevisiae overexpressing alkaline phosphatase. BMC Biotechnology 2014 14:42. 